\title{
ESTRATÉGIAS ARGUMENTATIVAS NO WEBJORNA- LISMO: um estudo semiolinguístico de um editorial do site Folha de S. Paulo
}

\author{
Paula Souza Pereira \\ (Universidade Estadual do Sudoeste da Bahia) \\ https://orcid.org/0000-0001-7747-7067 \\ Marcus Antônio Assis Lima \\ (Universidade Estadual do Sudoeste da Bahia) \\ https://orcid.org/0000-0001-8407-1866
}

\section{RESUMO}

Esta pesquisa pretende abordar, sob o ponto de vista da Teoria Semiolinguística, corrente teórico-metodológica formulada por Patrick Charaudeau, as estratégias discursivas contidas em um editorial que evoca a carência habitacional brasileira, publicado no webjornal Folha de S. Paulo, em 2018. Ademais, este artigo busca investigar as formas como o enunciador se posiciona perante os interlocutores, explorando a tríade fundamentada na relação entre sujeito argumentante, proposta sobre o mundo e sujeito-alvo (CHARAUDEAU, 2016). Mediante as observações efetuadas, destaca-se que a construção da fala do locutor, a partir do modo de organização argumentativo, implica a composição de sua imagem no discurso (AMOSSY, 2005).

PALAVRAS-CHAVE: Discurso; Argumentação; Semiolinguística; Webjornalismo. 


\title{
ARGUMENTATIVE STRATEGIES IN WEBJOURNALISM: a semiolinguistic study of an editorial on the site Folha de S. Paulo
}

\begin{abstract}
This research intends to approach the discursive strategies contained in an editorial that evokes the Brazilian housing shortage, published in Folha de S. Paulo web journal in 2018, from the point of view of the Semiolinguistic Theory, a theoreticalmethodological current enacted by Patrick Charaudeau. In addition, this article aims to investigate the ways that the enunciator stands before the interlocutors, exploring the triad based on the relation between the subject that argues, the proposition about the world and the target subject (CHARAUDEAU, 2016). Through the observations made, it is emphasized that the construction of the speaker's discourse, from the argumentative mode of organization, implies the composition of his image in the discourse (AMOSSY, 2005).
\end{abstract}

KEYWORDS: Discourse; Argumentation; Semiolinguistics; Web Journalism.

\section{Introdução}

Os estudos acerca do vínculo entre língua e sociedade são indispensáveis para a apreensão de um discurso. Benveniste (1976, p. 27) frisa que "a sociedade não é possível a não ser pela língua; e, pela língua, também o indivíduo". Por conseguinte, a percepção das singularidades do sujeito e das condições sociais que o contornam proporciona um amplo alicerce sobre as enunciações idealizadas e propagadas.

O desenvolvimento das Tecnologias da Informação e Comunicação (TICs) propiciou vantagens no tocante a agilidade na divulgação de acontecimentos e a interatividade dos sujeitos nos processos virtuais. Assim, os discursos produzidos para o meio digital adquiriram formatos mais dinâmicos, acompanhando a ascensão das novas plataformas. Logo, dis- 
cernir os propósitos dos discursos veiculados no ciberespaço contribui para a assimilação das estratégias tecidas com fins específicos.

Para Bakhtin (Volochínov) (2012), a palavra, no instante de sua expressão, revela-se como o produto das forças sociais. Benveniste (1976) enfatiza que o discurso é, ao mesmo tempo, emissário de uma mensagem e instrumento de ação, uma vez que o produtor se propõe como sujeito na ocasião em que envolve o outro.

$\mathrm{Na}$ web, a prática jornalística tem propiciado um espaço crescente e dinâmico para a interação do público leitor. Nesse local, a instância de produção das notícias se apropria dos recursos virtuais a fim de incorporá-los nas informações e, dessa forma, reforçar o vínculo com os interlocutores. Estes, por seu turno, se envolvem no processo narrativo, emitindo comentários, sugerindo e enviando matérias, participando de enquetes e grupos de discussão, entre outras tarefas.

Com o intuito de abranger as análises do linguista francês Patrick Charaudeau relativas ao modo de organização argumentativo ${ }^{1}$, procura-se traçar um panorama referente a aspectos dessa lógica. Com base no editorial intitulado "Carência imóvel", publicado no webjornal Folha de S. Paulo no dia 06 de maio de 2018, foram pautadas as formas como o enunciador se pronuncia, visando persuadir o público com seu discurso.

A estrutura da pesquisa está amparada nos debates que abarcam conceitos substanciais da Teoria Semiolinguística, noções essas aplicadas à exploração do discurso da Folha. Portanto, este trabalho mostra-se relevante, pois apura as intencionalidades do locutor em relação à produção jornalística, expandindo as discussões de ordem argumentativa no ambiente virtual.

\section{Abordagens iniciais: alguns pressupostos da Te- oria Semiolinguística}

A Teoria Semiolinguística (TS) surgiu em meados da década de 1980 e insere o discurso em uma problemática comunicacional e pragmática, sobrelevando a questão dos sujeitos e suas proposições, e classifica o ato de linguagem como produto de um contexto em que emissor e re-

1 Os modos de organização são procedimentos que utilizam categorias de língua para ordená-las em função das finalidades discursivas do ato de comunicação e podem ser concatenados pelos modos enunciativo, descritivo, narrativo, argumentativo (CHARAUDEAU, 2016). 
ceptor podem atribuir diferentes interpretações a expressões linguísticas (CORREAA-ROSADO, 2014). O ato de linguagem é originário de uma situação de troca, dependente de uma intencionalidade, e se organiza num espaço de restrições e num espaço de estratégias, produzindo significações pela interdependência de um circuito externo e de um circuito interno (CHARAUDEAU, 2005).

Diante disso, o termo Semiolinguística provém de "semio" (semiosis), destacando que a construção do sentido é realizada sob a direção de um sujeito com um projeto de influência em um quadro de ação, e "linguística", tratando-se da matéria das línguas naturais. Na ótica das ciências da linguagem, a Análise do Discurso é empírico-dedutiva, pois o analista parte de um material empírico, a linguagem, moldada em uma substância semiológica, a verbal (CHARAUDEAU, 2005).

Para tanto, o modelo da TS compreende uma troca entre dois parceiros, unidos pelos princípios da intencionalidade e da regulação, exercido numa situação de influência e regrado por um contrato. Este subentende que os seres pertencentes a um mesmo grupo firmam um elo de "conivência" e de cumplicidade quanto à utilização dos elementos da comunicação e fazem uso de estratégias para colocarem em cena suas intenções (PAULIUKONIS; GOUVÊA, 2012). Nesse sentido, o contrato de comunicação decorre das propriedades concernentes à situação de troca (dados externos - espaço do fazer) e dos atributos discursivos (dados internos - espaço do dizer) (CHARAUDEAU, 2006).

De acordo com o autor, os itens externos não são em sua essência linguageiros, mas semiotizados. Esses dados são agrupados em quatro classes (identidade, finalidade, propósito e dispositivo) e cada uma está ligada a um tipo de condição enunciativa da produção linguageira.

Charaudeau (2009) relata que a identidade do sujeito divide-se em identidade social, que precisa ser reforçada, recriada ou obscurecida pela conduta do falante, e identidade discursiva, que é edificada com base nos modos de tomada da palavra, na organização enunciativa e nos imaginários sociodiscursivos concebidos pelos diferentes tipos de saber.

A finalidade do ato de linguagem deve ser explorada em um movimento no qual um sujeito irá estabelecer a composição verbal e seu sentido oculto, jogo esse que dependerá da relação entre os protagonistas e destes com as possibilidades discursivas. Almeja-se responder à pergunta: "estamos aqui para dizer o quê?". Assim, requer ao investigador averiguar, dentro de uma problemática de influência, quais as visadas 
contidas no discurso. Charaudeau (2006) comenta sobre algumas delas: a prescritiva ("fazer fazer"), que leva o outro a agir de uma certa forma; a informativa ("fazer saber"), transmitindo conhecimento a quem presume não tê-lo - essa visada é efetuada pela mídia por meio da descrição-narração e pela explicação, explanando ao destinatário as causas e consequências dos fatos -; a incitativa ("fazer crer"), levando o interlocutor a refletir que o que se diz é verdadeiro (ou possivelmente verossímil); e a visada do pathos ("fazer sentir"), que provoca um estado emocional agradável ou não e propicia um consumo em conformidade com uma lógica comercial que é a de atrair a atenção da massa, na tentativa de sobreviver à concorrência.

O propósito está firmado num domínio de saber que condiz a um universo de discurso dominante pelo qual a troca deve reportar-se. E, enfim, o dispositivo é a condição que faz com que o ato de comunicação seja concebido de modo particular, conforme as provas materiais em que se progride (CHARAUDEAU, 2006).

Os dados internos são os comumente discursivos, que pretendem depreender os comportamentos dos sujeitos em detrimento das instruções nas restrições situacionais. Classificam-se em três espaços: locução, em que o sujeito falante deve justificar por que tomou a palavra e identificar a quem se dirige, para conquistar o direito de comunicação; relação, onde o locutor estabelece elos com o público; e tematização, local em que estão organizados os saberes e os temas (CHARAUDEAU, 2006).

A TS implementa um esquema com quatro interactantes incumbidos pela produção e interpretação do discurso. No circuito externo, lugar da instância situacional, atuam os parceiros, os sujeitos comunicante (EUc) e interpretante (TUi). No interno, espaço da encenação do dizer, estão os protagonistas, os sujeitos enunciador (EUe) e destinatário (TUd). O EUc é quem inicia o processo da palavra e quem articula a fala. O TUi é aquele que se encontra em uma relação de opacidade com a intencionalidade do sujeito produtor e que institui a si próprio como responsável pelo ato de interpretação produzido. O EUe é quem engendra efeitos de discurso no TUi e caracteriza-se como uma imagem de fala que oculta, em maior ou menor grau, o EUc. O TUd, por fim, é o interlocutor definido pelo produtor como destinatário ideal. O locutor tem controle sobre o TUd, já que o coloca em um local onde supõe que a intenção será transparente ao último (CHARAUDEAU, 2016). 
O teórico propala, a princípio, a conveniência de entender o conceito "comunicar" e define o ato de comunicação como um dispositivo no qual o falante ocupa posição central (ao falar ou escrever) quanto ao interlocutor. Ele acrescenta que os recursos integrantes desse artefato são a situação de comunicação, constituindo o ambiente físico e mental onde estão os parceiros, a língua, que institui o material verbal arquitetado em categorias linguísticas, os modos de organização do discurso, indicando os preceitos dependentes da finalidade comunicativa do sujeito (enunciar, descrever, contar e argumentar), e o texto, retratando o resultado do ato que, por sua vez, decorre de opções conscientes ou não por parte do locutor. Comunicar, portanto, não se restringe apenas à transmissão de informações, mas trata-se de proceder a uma encenação em que pensamento e linguagem estão reciprocamente vinculados.

Informar e comunicar são escolhas de efeitos de sentido para influenciar os sujeitos. Ao mais, a informação é considerada uma enunciação, pois estrutura um saber que necessita do conjunto de conhecimentos que o circunda, da situação em que está enquadrada e do aparato pelo qual é posta (CHARAUDEAU, 2006).

\section{A argumentação na concepção de Charaudeau}

No âmbito discursivo, a "argumentação" é alvo de muitas definições, dificultando seu estudo e sua apresentação (Charaudeau, 2016). Não obstante, existe uma tradição filosófica e linguística que remete a uma "história da argumentação". Desde a Antiguidade, os gregos situaram a argumentação no centro da Retórica.

Os gregos já eram conscientes de que "ter influência sobre outrem" não era o apanágio da razão, pois o ser humano é igualmente feito de paixões. É por isso que, desde aquela época, distinguia-se o que derivava da pura "ratio", para a qual devia existir uma técnica demonstrativa suscetível de "dizer a verdade", daquilo que derivava da "interação dos espíritos", para a qual devia existir uma técnica expressiva suscetível de "comover e captar" o interesse de um auditório (CHARAUDEAU, 2016, p. 202).

Há uma distinção que irá permear essa história: de um lado, o que pertence ao raciocínio, desprendido dos resíduos da psicologia humana, e de outro, o que está ligado à persuasão, que se mede pela capacidade de comoção através dos movimentos da psicologia (CHARAUDEAU, 2016). Em vista disso, uma linha filosófica continuou interessada nos as- 
pectos da linguagem, num prisma externo, para adaptá-la ao rigor de uma lógica pautada nas operações ajustadas pela linguagem matemática, até que linguistas retomassem a diferenciação feita pelos retóricos gregos.

Charaudeau (2016) cita alguns nomes que trabalharam com a argumentação, a exemplo de: Oswald Ducrot, linguista francês que sugere distinguir o estudo do raciocínio linguístico pelo confronto com as linguagens formais para apreciar as semelhanças e contrastes, e o estudo da argumentação, que tem como escopo nortear a sequência discursiva, representando maneiras de ação; Jean-Blaise Grize, professor suíço que opôs argumentação à demonstração; e do filósofo Chaim Perelman, com a Nova Retórica, tendência próxima a de Grize, perscrutando as técnicas que provocam ou aumentam a adesão às teses pronunciadas.

A partir dos anos 50, inicialmente nos Estados Unidos e em seguida na Europa, a psicossociologia interessou-se pelas mensagens persuasivas, bem como pela comunicação equiparada a um fenômeno causador de impactos nos grupos. Nessa disciplina, o conhecimento está baseado no condicionamento das situações de comunicação e na recepção da fala (CHARAUDEAU, 2016).

O semiolinguista aponta que suas concepções não aspiram substituir nenhuma existente, pois cada uma possui legitimidade própria. Nesse viés, o modo argumentativo exprime as noções destinadas à compreensão do discurso, sendo que variados atributos podem ser percebidos naquilo que está omisso.

Para que haja argumentação, precisam ser levantados alguns tópicos: uma proposta sobre o mundo que evoque um questionamento, um sujeito engajado quanto a esse questionamento e que formalize um critério para estipular uma verdade e um outro sujeito que se constitua como o alvo (CHARAUDEAU, 2016). Argumentar é, para o autor, uma atividade que, no olhar do argumentante, participa de uma busca de racionalidade, tipificada pelo ideal de verdade a respeito da explanação universal, e de influência, ligada a um ideal de persuasão. Ele reitera que o modo argumentativo outorga a construção explicativa das asserções. 


\section{0 discurso argumentativo em um editorial da Folha de S. Paulo}

Neste artigo, elegemos a vertente discursiva defendida por Patrick Charaudeau no intuito de analisar como o produtor das notícias tece suas argumentações.

O Grupo Folha é um dos principais conglomerados de mídia do Brasil. Ele controla, entre outros negócios, a Folha de S. Paulo, jornal de grande circulação, a empresa UOL, empreendimento de conteúdos de internet, a Plural, maior gráfica comercial do país, e o Datafolha, instituto de pesquisa bem conceituado ${ }^{2}$.

O webjornal foi criado em 1995 com o nome Folha Online e é o primeiro jornal em língua portuguesa em tempo real. O veículo desenvolve temas interativos para dispositivos móveis, publica cerca de 160 notícias diariamente e conta com uma audiência média de 28 milhões de visitantes únicos e 200 milhões de páginas visualizadas mensalmente. Conforme o site, a Folha segue princípios fincados no pluralismo e jornalismo crítico e independente ${ }^{3}$.

O jornalismo na web, afirma Ribas (2005), atingiu uma importante percepção enquanto modalidade diferenciada não apenas pelo novo suporte, mas por disponibilizar uma linguagem ajustada ao meio para cumprir sua função de noticiar os acontecimentos do cotidiano. Nesse ambiente, a sistematização das informações transcorre por intermédio do hipertexto, que interconecta os arquivos e impõe uma lógica para a exibição dos textos (MIELNICZUK, 2003).

O editorial é aquele que manifesta o parecer da empresa no que concerne a casos repercutidos. Cada editorial passa por um processo de conferência dos fatos, então, a diretoria toma decisões e o editorialista interpreta os pontos de vista a serem divulgados (MELO, 2003). Souza (2017) assevera que não há como designar o público-alvo de um editorial, todavia, sabe-se que ele procura nesse gênero uma opinião formada das ocorrências. Como o discurso tem a pretensão de fazer com que o leitor reflita sobre os assuntos, pode ser que o alocutário se envolva profunda-

2 Disponível em: <http://www1.folha.uol.com.br/institucional/> . Acesso em: 14 dez. 2018.

3 Disponível em: <http://www1.folha.uol.com.br/institucional/conheca_o_site_ da_folha.shtml>.Acesso em: 14 dez. 2018. 
mente com o texto, intentando encontrar a solução de um problema e se deparar com um sentimento de tranquilidade para sua consciência cidadã.

O editorial escolhido para investigação traz uma discussão do sistema habitacional brasileiro, expondo as necessidades de moradia enfrentadas pela população, as invasões de prédios em estado precário e a falta de fiscalização do governo no que se refere a imóveis pertencentes à União. Os argumentos estão ligados à tragédia que aconteceu no feriado do dia $1^{\circ}$ de maio de 2018, com o incêndio e o desabamento do Edifício Wilton Paes de Almeida, no centro de São Paulo. Mesmo em condições inabitáveis, o local havia sido ocupado. O editorial, abaixo na íntegra, foi publicado cinco dias após o fato.

\section{Carência imóvel}

Programas como o Minha Casa, Minha Vida não reduziram o déficit de moradias de boa qualidade; novas iniciativas precisam privilegiar regiões centrais

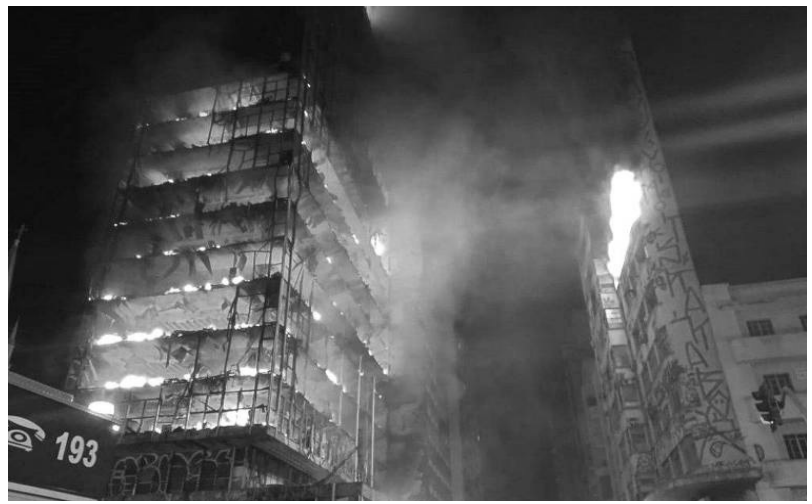

0 edifício Wilton Paes de Almeida, no centro de São Paulo, que desabou após incêndio - Corpo de Bombeiros/Divulgação

O incêndio que levou abaixo o edifício Wilton Paes de Almeida, no centro de São Paulo, despertou questionamentos sobre as invasões de prédios em condições precárias na maior cidade brasileira e debates acerca das crônicas carências nacionais na área de habitação.

É relativamente recente - data de 1996 - a formulação de uma metodologia mais confiável para quantificar as necessidades de moradia que se acumulam no país.

Estudos com base em dados do IBGE, realizados pela Fundação João Pinheiro em parceria com o Ministério do Planejamento, indicam que em 2015 (data do levantamento mais recente) registrou-se um déficit 
de 6,4 milhões de unidades, ou 9,3\% do total disponível.

A defasagem entre demanda e oferta de residências se mantém elevada, com oscilações nos últimos anos, a despeito de iniciativas do setor público - entre as quais se destaca, pelas dimensões (e também por equívocos conceituais), o Minha Casa, Minha Vida.

Bandeirada (sic) ex-presidente Dilma Rousseff (PT), o programa desembolsou mais de R $\$ 100$ bilhões (em valores corrigidos do Orçamento federal) desde 2009 e entregou até 2017, segundo dados oficiais, 3,7 milhões de habitações.

A explicação para o déficit persistente está não apenas no crescimento populacional, mas em fatores como a formação de novas famílias e aumento da expectativa de vida. Metade dele, ademais, refere-se a casos crescentes de custos considerados excessivos com aluguel.

Apura-se ainda o que se chama de déficit qualitativo, ou seja, relativo a moradias precárias, em geral sem contar com serviços básicos. São cerca de 9,8 milhões de domicílios no país sem acesso ou com acesso deficiente a infraestrutura, dos quais 3,2 milhões localizam-se em favelas ou em aglomerados semelhantes.

É óbvio que tais condições atingem, na grande maioria das vezes, os estratos populacionais de baixa renda, que dependem de subsídios estatais para obter moradia.

Tampouco há dúvidas de que as restrições orçamentárias se agravaram com a gestão irresponsável dos anos Dilma e a recessão econômica da qual o país se recupera de modo lento e tortuoso. Mais do que nunca, portanto, é necessário examinar formas mais eficientes para a ação do Estado.

Historicamente, os programas habitacionais — incluindo o Minha Casa, Minha Vida — têm privilegiado a construção de unidades prontas, não raro com arquitetura duvidosa ou mesmo opressiva, nas periferias das grandes cidades.

Esse tipo de alocação, ainda que necessário, gera problemas como a necessidade de investimentos adicionais em infraestrutura e mobilidade urbana. Seus beneficiários tendem a morar a longas distâncias de seus locais de trabalho, sem oferta satisfatória de transporte.

Não por acaso, urbanistas têm chamado a atenção para a necessidade de aproveitamento de áreas centrais, nas quais há serviços públicos como saneamento, linhas de trem, ônibus ou metrô - é precisamente o caso de São Paulo.

O Plano Diretor da cidade, diga-se, estimula a construção nesses corredores de transporte e tem propiciado alguns empreendimentos relevantes. Chama a atenção, porém, que não tenham saído do papel projetos para a reutilização de regiões pós-industriais e outras áreas que comportariam maior adensamento.

Há, sem dúvida, iniciativas para reverter o esvaziamento do centro, 
como a transferência da sede de órgãos públicos. Também se verificam lançamentos de pequenos apartamentos e alguma renovação do comércio e de moradias antigas.

Não é o bastante, contudo, para promover uma oferta mais significativa de imóveis, em especial para os setores de renda baixa.

O processo de abandono e degeneração de edifícios permanece, e sua reversão esbarra, entre outros fatores, nos elevados custos de reformas (em geral, é mais barato construir um novo prédio do que recuperar um antigo deteriorado) e no relativo desinteresse do setor público e do mercado.

À sombra desse quadro prosper (sic) a indústria das invasões, em que alguns movimentos chegam a ser instrumentalizados por grupos ligados à criminalidade, em especial ao tráfico de drogas.

É de esperar das autoridades governamentais, em todos os níveis, que zelem ao menos por condições mínimas de segurança e salubridade nessas edificações. Lamentavelmente o que se vê, no mais das vezes, é descaso, abandono e ausência de fiscalização - um convite a tragédias como a que ocorreu no feriado do Dia do Trabalho.

Editorial da Folha de S. Paulo, 06 mai. 2018.

Fonte: https://www1.folha.uol.com.br/opiniao/2018/05/carenci-imovel.shtml?utm_ source=folha\&tutm_medium=site\&tutm_campaign=topicos?cmpid=topicos

Levando em consideração o arcabouço teórico sustentado por Charaudeau, entendemos que no contrato midiático a encenação ocorre no momento em que o editorialista (EUc), reconhecido em nome de um saber certificado institucionalmente, assume uma identidade discursiva (EUe), implementando seus posicionamentos sobre o assunto. O EUe tenta alcançar, dentre os interpretantes (TUi), os sujeitos destinatários (TUd), leitores passíveis de absorver o que a mídia dita.

A informação constitui a finalidade primordial do relato. Contudo, na medida em que os fatos são expostos, certas visadas são inseridas na notícia com objetivos variados. Além disso, o argumentante arquiteta o discurso num lugar virtual que possibilita a incorporação de elementos que podem fortalecer seu pensamento. A distribuição de links no texto permite o acesso a inúmeras matérias relacionadas à principal.

O enunciador atua em um duplo espaço de credibilidade e de captação. Destarte, para o falante, a credibilidade está assentada na necessidade de que se creia nele, seja em relação à verdade das observações ou no que ele pensa. Logo, o argumentante se engaja no discurso a partir da seleção de expressões intencionais. 
Pela captação, o sujeito pretende fazer com que o parceiro da troca comunicativa participe de seu projeto de intencionalidade. Com isso, o objetivo do argumentante centra-se na visada do "fazer crer", ao adotar atitudes polêmicas, questionando pareceres, e atitudes de dramatização, por meio da apresentação de acontecimentos com carga dramática, transmitindo emoção (CHARAUDEAU, 2009).

O locutor, então, introduz seu discurso, direcionando-o a interlocutores específicos, planejando pactuar relações de proximidade com os mesmos. Para isso, usa o modo de organização argumentativo, buscando, estrategicamente, a adesão dos leitores às posturas por ele defendidas.

O título do editorial é sugestivo e causa um grande impacto, pois expede o dilema residencial deparado pela sociedade. A expressão "carência" recorre sutilmente à visada do pathos, salientando as privações relativas à falta de domicílios suficientes para atender os indivíduos. $\mathrm{O}$ editorialista constrói um raciocínio avaliativo, com argumentos persuasivos para conduzir o TUd a uma dedução previamente idealizada.

A proposta esteia-se na afirmação de que alguns projetos governamentais que oferecem condições para o financiamento de moradias a famílias de baixa renda, como o Minha Casa, Minha Vida não contribuíram para a redução do déficit de residências e que se precisa privilegiar iniciativas que contemplem as regiões centrais das cidades. $\mathrm{O}$ sujeito argumentante engendra seu discurso a um público-alvo, assinantes ou não ${ }^{4}$ do webjornal.

Ademais, a primeira parte do subtítulo contém um procedimento discursivo, reportando à "comparação por semelhança":

"Programas como o Minha Casa, Minha Vida não reduziram o déficit de moradias de boa qualidade". (grifo nosso)

A comparação empregada pelo termo "como" põe em evidência o programa do governo e as dificuldades no oferecimento de habitações em condições satisfatórias, reforçando o julgamento levantado.

Na sequência, a foto utilizada também acarreta um efeito patêmico, pois evidencia as proporções do incêndio e a gravidade do incidente. Charaudeau (2006, p. 89) diz que "nas mídias, o meio mais eficaz de designação é a imagem".

O autor estrutura a relação argumentativa em uma asserção de par-

$4 \mathrm{O}$ acesso às informações da Folha Digital é limitado. A leitura é livre até cinco notícias por mês. Em seguida, exige-se um cadastro que possibilita o acesso a mais cinco. 
tida (A1), correspondente a um dado ou premissa que consiste em fazer com que seres existam, atribuindo-lhes propriedades e descrevendo suas ações; uma asserção de chegada (A2), ligada à conclusão e legitimidade da proposta; e uma (ou mais) asserção de passagem, similarmente chamada de prova, inferência ou argumento, segundo a conjuntura em que está inscrita. No texto, isso ocorre da seguinte forma:

\section{Quadro 1 - A RELAÇÃO ARGUMENTATIVA}

\begin{tabular}{|c|c|c|}
\hline Asserção de partida & Asserção de passagem $^{5}$ & Asserção de chegada \\
\hline $\begin{array}{l}\text { “O incêndio que } \\
\text { levou abaixo o } \\
\text { edificio Wilton } \\
\text { Paes de Almeida, } \\
\text { no centro de São } \\
\text { Paulo, despertou } \\
\text { questionamentos } \\
\text { sobre as invasões } \\
\text { de prédios em } \\
\text { condições } \\
\text { precárias na } \\
\text { maior cidade } \\
\text { brasileira e } \\
\text { debates acerca } \\
\text { das crônicas } \\
\text { carências } \\
\text { nacionais na área } \\
\text { de habitação”. } \\
\text { (Al) }\end{array}$ & $\begin{array}{l}\text { Argumentos: } \\
\text { - "É óbvio que tais condições [déficit quantitativo } \\
\text { e qualitativo das moradias] atingem, na grande } \\
\text { maioria das vezes, os estratos populacionais de } \\
\text { baixa renda, que dependem de subsídios estatais } \\
\text { para obter moradia”. } \\
\text { - "O processo de abandono e degeneração de } \\
\text { edificios permanece, e sua reversão esbarra, } \\
\text { entre outros fatores, nos elevados custos de } \\
\text { reformas (em geral, é mais barato construir um } \\
\text { novo prédio do que recuperar um antigo } \\
\text { deteriorado) e no relativo desinteresse do setor } \\
\text { público e do mercado”. } \\
\text { - "À sombra desse quadro prosper (sic) a } \\
\text { indústria das invasões, em que alguns } \\
\text { movimentos chegam a ser instrumentalizados por } \\
\text { grupos ligados à criminalidade, em especial ao } \\
\text { tráfico de drogas”. }\end{array}$ & $\begin{array}{c}\text { "É de esperar das } \\
\text { autoridades } \\
\text { governamentais, } \\
\text { em todos os níveis, } \\
\text { que zelem ao } \\
\text { menos por } \\
\text { condições } \\
\text { mínimas de } \\
\text { segurança e } \\
\text { salubridade } \\
\text { nessas } \\
\text { edificações. } \\
\text { Lamentavelmente } \\
\text { o que se vê, no } \\
\text { mais das vezes, é } \\
\text { descaso, } \\
\text { abandono e } \\
\text { ausência de } \\
\text { fiscalização". } \\
\text { (A2) }\end{array}$ \\
\hline
\end{tabular}

Fonte: Adaptação do esquema de Charaudeau (2016, p. 210).

$\mathrm{O}$ quadro difunde o ponto de partida do editorial, mediante o enunciado demarcado como A1. Nele, o argumentante discute a repercussão do acontecimento e os debates em torno do tema. No A2, o EUe expõe seu julgamento meio ao caso, ponderando que as autoridades devem zelar pela segurança e salubridade nas edificações. Em virtude disso, o enunciador incita uma série de provas que comprovam suas posições ao relatar que "é óbvio" que os empecilhos, na maioria das vezes, atingem as ca-

5 No texto, existem inúmeros argumentos que justificam como o locutor estabelece a relação entre o A1 e o A2. Selecionamos alguns deles para exemplificar a 
madas mais pobres da população; que existe um "relativo desinteresse" do setor público e do mercado quanto à manutenção dos prédios; e que por conta da ausência de fiscalização, grupos criminosos têm invadido os referidos locais.

Além disso, os modos de encadeamento, apreciados por Charaudeau (2016) como conexões argumentativas assentadas pela causalidade, estão presentes no texto quando o editorialista cita, pelo estilo "finalidade", a preposição "para":

"É relativamente recente — data de 1996 — a formulação de uma metodologia mais confiável para quantificar as necessidades de moradia que se acumulam no país". (grifo nosso)

As relações instauradas entre as asserções, devido à aplicação desse termo, permitem estipular as condições e o valor de verdade da proposta em geral, complementando as argumentações. Em seguida, para fundamentar o efeito de verdade do relato, o EUe alude a um argumento de autoridade, baseado em dados do Instituto Brasileiro de Geografia e Estatística (IBGE), feitos pela Fundação João Pinheiro em parceria com o Ministério do Planejamento, que indicam que no ano de 2015 houve registro de um déficit de 6,4 milhões de moradias, o equivalente a 9,3\% do total disponível.

Essa referência avulta o discurso do argumentante, porquanto ele comenta sobre a manutenção elevada da defasagem entre demanda e oferta de residências, com oscilações nos últimos anos, frisando os equívocos conceituais do programa Minha Casa, Minha Vida, bandeira da ex-presidente Dilma Rousseff (PT). O EUe enfatiza que não somente o crescimento populacional, mas fatores como a formação de novas famílias, o aumento da expectativa de vida e os custos crescentes com aluguéis têm favorecido a expansão do déficit. Outrossim, o locutor assinala que são cerca de 9,8 milhões de domicílios no país sem acesso ou com acesso insatisfatório à infraestrutura, sendo que desses, 3,2 milhões estão situados em favelas ou em aglomerados similares.

Dessa forma, a maneira de problematizar desvela escolhas operadas pelo argumentante no discurso. Pela delegação de autoridade, que visa outorgar autenticidade e eficácia às asserções, o argumentante justifica seus posicionamentos e concede ao TUi os meios para julgar as informações. 
Há ainda o registro do modo de "restrição". Esse encadeamento é responsável pela associação de causa e consequência, implementando, ao final, uma asserção contrária à conclusão esperada:

"Há, sem dúvida, iniciativas para reverter o esvaziamento do centro, como a transferência da sede de órgãos públicos. Também se verificam lançamentos de pequenos apartamentos e alguma renovação do comércio e de moradias antigas.

Não é o bastante, contudo, para promover uma oferta mais significativa de imóveis, em especial para os setores de renda baixa". (grifo nosso)

Nesse fragmento, o enunciador salienta a existência de ações práticas voltadas ao aproveitamento de áreas centrais no sentido de promover a oferta de imóveis. Porém, ele encerra seu parecer defendendo que tais atitudes não são suficientes para resolver a dificuldade.

Consoante Charaudeau (2016), o dispositivo argumentativo, concebido como um dos componentes de encenação, é definido por três fatores: proposta, correspondente a uma tese, proposição, tomada de posição que parte de uma indagação que põe em causa a proposta, e persuasão, evidenciando esse raciocínio. Esses esquemas estão caracterizados pelos períodos:

Proposta 1: (...) "as restrições orçamentárias se agravaram com a gestão irresponsável dos anos Dilma e a recessão econômica da qual o país se recupera de modo lento e tortuoso".

Proposição 1: “Tampouco há dúvidas”(...).

Persuasão 1 (justificativa): "Mais do que nunca, portanto, é necessário examinar formas mais eficientes para a ação do Estado".

A situação de troca no discurso é monologal, pois o sujeito elabora a totalidade do texto argumentativo. $\mathrm{O}$ enunciador mostra-se empenhado em relação à proposta, ao discutir a defasagem orçamentária agravada na gestão, julgada por ele como "irresponsável", dos anos Dilma, e à recessão econômica pela qual o Brasil se recupera de modo "lento e tortuoso", delineando, dessa maneira, sua justificativa.

Na sucessão, ele emana um juízo irônico ao arguir que o Programa Minha Casa, Minha Vida prioriza a edificação de unidades prontas nas periferias e que podem apresentar "arquitetura duvidosa ou mesmo opressiva". 
Proposta 2: "Historicamente, os programas habitacionais — incluindo o Minha Casa, Minha Vida — têm privilegiado a construção de unidades prontas, não raro com arquitetura duvidosa ou mesmo opressiva, nas periferias das grandes cidades".

Proposição 2: "Não por acaso, urbanistas têm chamado a atenção para a necessidade de aproveitamento de áreas centrais" (...). (grifo nosso)

Persuasão 2 (justificativa): "Esse tipo de alocação, ainda que necessário, gera problemas como a necessidade de investimentos adicionais em infraestrutura e mobilidade urbana".

Os excertos designam a tentativa de persuasão difundida para direcionar a visão dos leitores a certas tendências opinativas. Ao comentar acerca do programa habitacional, o enunciador avalia que esse tipo de alocação demanda investimentos em infraestrutura e mobilidade urbana, já que os beneficiários tendem a residir longe dos locais de trabalho.

Outras marcas referentes ao dispositivo argumentativo estão na série:

Proposta 3: "O processo de abandono e degeneração de edifícios permanece, e sua reversão esbarra, entre outros fatores, nos elevados custos de reformas (em geral, é mais barato construir um novo prédio do que recuperar um antigo deteriorado) e no relativo desinteresse do setor público e do mercado".

Proposição 3: "É de esperar das autoridades governamentais, em todos os níveis, que zelem ao menos por condições mínimas de segurança e salubridade nessas edificações”. (grifo nosso)

Persuasão 3 (justificativa): "Lamentavelmente o que se vê, no mais das vezes, é descaso, abandono e ausência de fiscalização — um convite a tragédias como a que ocorreu no feriado do Dia do Trabalho".

Ao passo que esboça o episódio, o editorialista toma uma posição rígida quanto ao estabelecimento de ações transformadoras, pois reconhece que o processo de degeneração de edifícios se mantém. Entretanto, segundo ele, a reversão desse impasse é confrontada pelos altos custos com reformas e pelo "desinteresse" do setor público e do mercado. Do mesmo modo, expõe uma investida persuasiva acentuando que as autoridades devem fiscalizar as edificações. Ao final, ele recorda que a tragédia ocorreu no feriado do Dia do Trabalho, trazendo uma reflexão das condições atuais de ofertas de emprego no país. 
O chamado "tempo forte", um dos procedimentos de composição que, em consonância com Charaudeau (2016), tem o encargo de sublinhar momentos da evolução argumentativa para firmar uma hierarquia e despertar a atenção do ouvinte, também consta no texto, quando o sujeito exterioriza sua indignação pela inércia dos responsáveis na execução dos planos de reutilização de áreas para comportar moradias.

"Chama a atenção, porém, que não tenham saído do papel projetos para a reutilização de regiões pós-industriais e outras áreas que comportariam maior adensamento". (grifo nosso)

Isto posto, ao emitir suas visões acerca do assunto, o locutor constrói sua imagem vinculada à própria enunciação (AMOSSY, 2005). Destarte, o EUe concatenou todos os argumentos para suscitar o interesse dos leitores frente à intercorrência. A ordenação dos enunciados foi planejada com o propósito de influenciar o receptor, conduzindo-o à aceitação e divulgação do discurso relatado.

\section{Considerações finais}

A linguagem assume um papel fundamental na expressão de determinadas esferas de pensamento. Em concordância com Benveniste (1976), a conjuntura inerente ao exercício da linguagem atribui ao discurso um ofício duplo: para o produtor, simboliza a realidade; e para o ouvinte, recria a realidade. Nesse caso, compreender a produção de informações na web é essencial para averiguar as intenções contidas no texto.

Em consequência disso, notou-se que noções empregadas com sentidos diversos encadearam os enunciados no editorial, tornando visíveis, ou implícitos, ícones argumentativos que guiaram o discurso. A ação e a influência promovida pelo sujeito externaram traços que sinalizaram suas reflexões. Constatou-se que foram utilizados, intencionalmente, várias estratégias e recursos linguísticos no jogo argumentativo. $\mathrm{O}$ falante participou de uma encenação em que coordenou a fala em função de sua identidade, do interlocutor idealizado preliminarmente e do que já havia sido dito (Charaudeau, 2016).

O webjornal mostrou que apesar dos planos formulados pelo governo para amenizar o problema da falta de moradias, o cenário ainda permanece dramático, necessitando de aplicações mais efetivas. Por meio das premissas, dos argumentos e da conclusão à tese aludida, o enunciador exprimiu sua visão e pontuou soluções para o contratempo, exteriori- 
zando posição de total comprometimento diante da proposta e estimulando a formação da opinião pública.

O estudo tenciona contribuir para a ampliação das observações voltadas ao exame do discurso midiático na web, com a perspectiva de expandir os olhares em torno das práticas argumentativas no ciberespaço.

\section{REFERÊNCIAS}

AMOSSY, Ruth (Org.). Imagens de si no discurso: a construção do ethos. Trad. Dilson Ferreira da Cruz, Fabiana Komesu e Sírio Possenti. São Paulo: Contexto, 2005.

BAKHTIN, Mikhail. (VOLOCHÍNOV, Valentin). Marxismo e filosofia da linguagem: problemas fundamentais do método sociológico na ciência da linguagem. Trad. Michel Lahud e Yara Frateschi Vieira. 13. ed. São Paulo: Hucitec, 2012.

BENVENISTE, Émile. Problemas de linguística geral. Trad. Maria da Glória Novak e Luiza Neri. São Paulo: Ed. Nacional, 1976.

CARÊNCIA imóvel. Folha de S. Paulo, São Paulo, 06 mai. 2018. Disponível em: $<$ https://www1.folha.uol.com.br/opiniao/2018/05/carencia-imovel.shtml?utm_ source $=$ folha\&utm_medium $=$ site\&utm_campaign $=$ topicos $? \mathrm{cmpid}=$ topico $>$. Acesso em: 21 dez. 2018.

CHARAUDEAU, Patrick. Discurso das mídias. Trad. Angela M. S. Corrêa. São Paulo: Contexto, 2006.

Identidade social e identidade discursiva, o fundamento da competência comunicacional. In: PIETROLUONGO, Márcia (Org.). O trabalho da tradução. Rio de Janeiro: Contra Capa, 2009, p. 309-326. Disponível em: <http:// www.patrick-charaudeau.com/Identidade-social-e-identidade.html>. Acesso em: 15 nov. 2018.

Linguagem e discurso: modos de organização. Coord. trad. Angela M. S. Corrêa e Ida Lucia Machado. 2. ed. São Paulo: Contexto, 2016.

. Uma análise semiolinguística do texto e do discurso. In: PAULIUKONIS, Maria Aparecida Lino; GAVAZZI, Sigrid (Org.). Da língua ao discurso: reflexões para o ensino. Rio de Janeiro: Lucerna, 2005. p. 11-27. Disponível em: $<$ http://www.patrick-charaudeau.com/Uma-analise-semiolinguistica-do.html $>$. Acesso em: 21 dez. 2018. 
CORRÊA-ROSADO, Leonardo Coelho. Teoria semiolinguística: alguns pressupostos. Revista Memento, Betim, v. 5, n. 2, jul./dez. 2014. Disponível em: $<$ http://periodicos.unincor.br/index.php/memento/article/view/1826>. Acesso em: 21 dez. 2018.

MELO, José Marques de. Jornalismo opinativo: gêneros opinativos no jornalismo brasileiro. 3. ed. Campos do Jordão: Mantiqueira, 2003.

MIELNICZUK, Luciana. Jornalismo na web: uma contribuição para o estudo do formato da

notícia na escrita hipertextual. Salvador, 2003. 246f. Tese (Doutorado em Comunicação e Cultura Contemporâneas) - Faculdade de Comunicação, Universidade Federal da Bahia. Disponível em: <http://www.scribd.com/doc/12769270/Jornalismona-

web-uma-contribuicao-para-o-estudo-do-formato-da-noticia-na-escrita-hiper textual>. Acesso em: $21 \mathrm{dez} .2018$.

PAULIUKONIS, Maria Aparecida Lino; GOUVÊA, Lúcia Helena Martins. Texto como discurso: uma visão semiolinguística. Revista do Programa de Pós-Graduação em Letras da Universidade de Passo Fundo, v. 8, n. 1, p. 49-70, jan./ jun. 2012. Disponível em: <http://seer.upf.br/index.php/rd/article/view/2638>. Acesso em: 13 dez. 2018.

RIBAS, Beatriz. A narrativa webjornalística: um estudo sobre modelos de composição no ciberespaço. Salvador, 2005. 205f. Dissertação (Mestrado em Comunicação e Cultura Contemporâneas) - Faculdade de Comunicação, Universidade Federal da Bahia. Disponível em: <http://gjol.net/wp-content/uploads/2012/12/2005_ribas_dissertacao.pdf>. Acesso em: 21 dez. 2018.

SOUZA, Karen Pereira Fernandes de. Efeitos patêmicos em texto midiático: análise de um editorial de jornal. In: GOUVÊA, Lúcia Helena Martins (Org.). Argumentação pela emoção: um caminho para persuadir. Rio de Janeiro: UFRJ, 2017. p. 213-246.

Recebido em: 13/12/2018

Aceito em: 06/06/2019 